Received: November 29, 2017

\title{
Sentence Meaning Comprehension Strategies for Foreign Language Learners: Attribute-space-time Based Events, Event Structures and the Representations*
}

\author{
Xiaolan Gan ${ }^{1}$ \\ Sichuan University, Sichuan University of Science and Engineering
}

\begin{abstract}
The study of sentence patterns plays a very important role in foreign language learning. Linguistic researchers have analyzed and discussed sentence meaning structures and their representation from various angles, but few of them except theories of event structures study from the origin of sentence production. The current mainstream theories of the event structures mainly introduce the event structures by the characteristics of verbs. These theories are bound to lead to the existence of many inexplicable linguistic expressions within their own theoretical frameworks. Adapting to the trend of integrated study of events, the present study attempts to integrate the basic views of events in the various fields and puts forward a view of attribute-space-time based events. On that basis, this study further defines and classifies the events and finally represents their event structures. The mastery of attribute-space-time events, event structures and their representations can help foreign language learners to better grasp the laws of foreign language and to learn them more effectively.
\end{abstract}

\section{Keywords}

Foreign Language Learning $\bullet$ Theories of Event Structures $\bullet$ The Attribute $\bullet$ The Space $\bullet$ The Time

\footnotetext{
* The research was supported by the Scientific Research Fund of SiChuan Provincial Education Department (28SB0487)

1 Correspondence to: School of Foreign Languages and Cultures, Sichuan University, Chengdu Sichuan 610065, China; School of Foreign Languages, Sichuan University of Science and Engineering, Zigong Sichuan 643000, China. Email: ganxiaolan@suse.edu.cn
}

Citation: Gan, X. L. Sentence Meaning Comprehension Strategies for Foreign Language Learners: Attribute-space-time Based Events, Event Structures and the Representations. Educational Sciences: Theory \& Practice, 18(5), 2162-2175. http://dx.doi.org/10.12738/estp.2018.5.116 
Gan / Sentence Meaning Comprehension Strategies for Foreign Language Learners: Attribute-space-time Based Events...

The study of sentence patterns plays a very important role in foreign language learning. The comprehension and production of special sentence patterns is the focus and difficulty of learning. Linguistic researchers have analyzed and discussed the semantic structure of special sentence patterns from various angles, but rarely explored them from the origin of sentence production. The present study starts from the objective world, proposes that one of the important steps of sentence production is that the speaker conceptualizes the real events in the objective world into attribute-space-time linguistic events. Mastering the type of attribute-space-time linguistic events, event structures and their representations will be helpful to foreign language learner.

\section{From events to event structures}

What are events? In the field of ontology, events are considered to be actions which occur in a certain time and space. In the field of philosophy, events are regarded as concrete facts which are gone forever in the world. In the field of cognitive science, events are units of people's knowing and understanding of the world. And in the field of linguistics, events can be defined both in a narrow sense and a broad sense. In a narrow sense, Davidson (2001) considers events to be behavioral sentences with the complete tenses and aspects. In a broad sense, Maienborn (2008) agrees with Bach (2002) and defines events as the states of affairs (i.e. eventualities). Ritter and Rosen (1998) make a compromise and regard all non-static situations (non-statives) as events.

Events have not been seriously considered in the field of linguistics for a long time. Reichenbach (1947) firstly regards an event as an argument in the predicate logic but it is Davidson (2001) who turns it into an object of linguistic studies. Until the 1990s, events begin to attract the attention of researchers in the fields of logical semantics, lexical semantics and syntax (Tenny \& Pustejovsky, 2000). In the field of logical semantics, logical semantists find that it is necessary to turn to some factors related to event semantics (such as causality, tense and aspect features, etc.) in order to understand the truth conditions for sentences. In the field of lexical semantics, lexical semantists premote that the syntactic representations of verbs are largely determined by the structures of the events (i.e. the event structures) encoded by the verbs. In the field of syntax, the researchers also present that event structures and syntactic structures are likely isomorphic from a large amount of factual evidences. Even if it is not the case, there must be derivative relationships between them.

Both logical semantists and lexical semantists focus on events, particularly the representations of the event structures. Their differences lie in that logical semantists regard events as a indecomposable whole and focus on the study of the external structures of events from top to bottom (i. e. the structures between events), while the lexical semantists considers events as a decomposable polymer and focus on to the internal structures of events from bottom to top. With the deepening of the study of events, the two schools begin to move towards integration, that is, logical semantists begin to pay attention to the internal structures of the events and lexical semantists begin to pay attention to the external structures of the events. In any case, event structures (including both the internal structures and external structures) have become the common topics for most the current linguists. 


\section{Previous studies on the event structures and their representations}

Theories of event structures refer to those linguistic theories which mainly study the representations of the event structures and the mapping processes from the event structures to their syntactic structures (Tenny \& Pustejovsky, 2000). Although many linguistic researchers believe that the event structures are the key factors to determine the syntactic structures, different researchers have different opinions on the conceptualizations of the events, that is, the combinations and representations of the event structures. Generally speaking, there are mainly three influential theories of event structures: the local approach, the aspectual approach and the causal approach.

\section{The local approach}

The local approach is first proposed by Gruber in his doctoral dissertation Studies in Lexical Relations (Gruber, 1965) and further improved by Jackendoff (1990a, 1990b, 2003). This approach treats all verbs as motion or locative verbs. Correspondingly, events are divided into motion or locative events.

In his above-mentioned literatures, Jackendoff manages to represent the related events structures of the linguistic events (the lexical semantic representations in Jackendoff's terms). He uses $G O, B E$ and $S T A Y$ to represent motion verbs and two kinds of locative verbs respectively. He believes that the events represented by the above three kinds of verbs could sometimes be nested within causative events (the causative verbs are CAUSE). Thus, Jackendoff divides the lexical semantic representations into two tiers: one is the thematic tier, which mainly expresses the semantic information of the motion and locative events; the other is the action tier, which mainly expresses the semantic information of the causative events.

The local approach has at least the following limitations. At first, the thematic tier has nothing to do with argument realization, although the action tier of this approach is to a certain extent related to it. Secondly, some verbs such as "cry", "play" and "laugh" are difficult to be considered to be motion verbs or locative verbs. Finally, this approach is difficult to explain some special syntactic-semantic phenomena, such as the argument reversion caused by the psychological verb "frighten".

\section{The aspectual approach}

In order to explain the argument reversion caused by "frighten", some researchers turns to another theory of the event structures: the aspectual approach. This approach refers to the study of syntax-semantic interface from the perspective of "aspect", which is related to the temporal characteristics of the linguistic events, such as "continuity", "repetition" and so on. This approach generally adopts the verbal classification method of Vendler (Vendler, 1957), which classifies verbs into four categories: states, activities, achievements and accomplishments. Accordingly, events can be divided into events of states, events of activities, events of achievements and events of accomplishments. 
Gan / Sentence Meaning Comprehension Strategies for Foreign Language Learners: Attribute-space-time Based Events...

Grimshaw (1990) is the just person who manages to apply the aspectual approach to explain the argument inversion of psychological verbs. Like Jackendoff, Grimshaw also believes that there are both an action tier (i.e. causative tier) and a thematic tier for representations of the lexical semantics; however, he disagrees with Jackendoff and considers that there is a linking relationship between semantics and syntax. He further proposes that the linking is determined both by the thematic roles in the thematic tier and the aspectual roles in the action tier. And he regards that the aspectual role "causer" is more prominent and always projected as the syntactic subject. Thus "the building" in the expression "the building frightened the tourists" is certainly projected as the subject because it take the aspectual role "causer". Although Grimshaw successfully explains the argument inversion caused by the psychological verbs "frightern", he does not go any further to explain what "causer" is and why the "causer" is more prominent.

Tenny et al., (1994) even argues that aspectual roles are the only factors to determine the syntactic realization, that is, the linking between semantic arguments to syntactic positions. He assumes that the aspectual properties figured in the linking between syntax and semantics are expressed through "aspectual roles", which are assigned by a verb to its arguments.

The aspectual approach (Tenny, 1994) has met with a lot of challenges. First of all, the mapping constraints from aspectual features to syntax proposed by Tenny do not reflect the linguistic facts. Jackendoff (2003) argues that not all objects that are subject to the movement or change must be direct objects, and in some cases they can be subjects as well. In addition, Tenny's assertion that "only aspectual features are the visible part of the universal linking principle" has aroused great controversy. In fact, some transformations of sentence structures, such as case transfers, with/against transformations and so on, are not necessarily driven by aspectual features.

\section{The causal approach}

Croft (1991) proposes another theory of the event structures: the causal approach. Based on the relationships between event participants, Croft's events are analyzed as the causative chains among the participants. Specifically, a causative chain is made up of a series of links, each of which links two participants through verbs. And one participant could play roles in multiple links at the same time. Besides, a very important concept for the causal approach is "profile". The same causative chain can be "profiled" in different ways, meaning that verbs can be associated with different syntactic forms.

The syntactic realization of semantic arguments can be reasonably explained by the positions of the participants in the causative chain. However, like the local approach and the aspectual approach, the causal approach encounters the same dilemma, that is, not all the relationships between the event participants can be expressed as causative relations. Another shortcoming for this approach is that the motivation of "profile" has not yet been explained.

\section{Summary}

In summary, all the above-mentioned approaches for the event structures have faced with some problems, which are caused by their explorations of syntactic-semantic interfaces only from one single-dimensional angle. To be more precisely, the local approach is a way of studying events from the spatial dimension alone. The 
Gan / Sentence Meaning Comprehension Strategies for Foreign Language Learners: Attribute-space-time Based Events...

aspectual approach is a way of looking at events from the temporal dimension alone. And the causal approach is a method of studying events from the point of view of the interrelationship (i.e. causation) between two participators alone. Then why all the three approaches do their researches only from one angle? This is because all of them study the syntax-semantic interfaces only based on the introduction of verbs into the event structures.

\section{Attribute-space-time based event structures and their representations}

\section{Presentation of an integrated view of events}

As mentioned earlier, all the three current theories of the event structures do their researches from the perspective of verbs so that they face with difficulty of explaining some of the plight of the linguistic phenomena within their own theoretical frameworks. In recent years, many researchers have advocated the analyses of the types and structures of events from the perspective of the overall meaning of sentences, and proposed that events should be regarded as a whole. That is, the structures of events (Verkuyl, 1972; Dowty, 1979; Rosen, 1996) should be comprehensively analyzed from the key factors (such as the time, the space, the cause, the change, etc.) of the events.

Adapting to the trend of comprehensive development of event structure theories, the present study presents a new integrated view of events. Different from other theories, this view is an integrated view of events that integrates the basic opinions of "events" in the fields of the ontological, philosophical, cognitive and linguistics. Specifically speaking, the integrated view of events in this paper mainly includes the following three viewpoints:

Viewpoint 1 (the integrated view of event types). Events include real events and linguistic events. The linguistic events should first of all be the conceptualization of the real events in the objective world.

Viewpoint 2 (the integrated view of real events). A real event refers to the state or change of the nature of an objective object in a certain time and space, including all the static states and dynamic changes of the objective object in the objective world.

Viewpoint 3 (the integrated view of linguistic events). A linguistic event refers to the whole semantic contents of a real event, which can be expressed as different linguistic event types according with profiling or concealing the compositive elements of the related linguistic event and can be finally encoded into specific linguistic expressions.

\section{Combinations of the elements of linguistic events}

According to the second viewpoint of the integrated view of events, the constitution of a real event should include at least three elements, namely "the attribute (a)", "the space (s)" and "the time (t)" of a certain object. Among them, "the attribute" is related to the object's properties or characteristics except the time and the space; "the space" is related to the object's spatial location, distribution and correlation; and "the time" is related to the 
Gan / Sentence Meaning Comprehension Strategies for Foreign Language Learners: Attribute-space-time Based Events...

$\overline{\text { object's temporal point, interval, and properties of a change in motion that occur at a certain point in time or }}$ over a interval of time.

According to Viewpoint 1, linguistic events are the conceptualization of real events, linguistic events should also logically include the three elements (i.e. the attribute, the space and the time) mentioned above. This paper applies the set theory to combine them and then gets the set of the elements of linguistic events, that is:

$$
\mathrm{E}_{\mathrm{e}}=\{\mathrm{a}, \mathrm{s}, \mathrm{t}\}
$$

Where "E" refers to the element, "e" indicates the linguistic event, "a" is the attribute, "s" is the space and " $\mathrm{t}$ " is the time.

If the speaker uses language to describe the real events in the objective world, then the ideal situation is that the speaker can describe them with complete accuracy in the language he or she uses. But this depends on two conditions: first, the speaker believes that there is such a necessity; second, the language used by the speaker has such a possibility. In fact, no one needs to describe every detail of a real event, and no language can do so completely and effectively. Therefore, when speakers conceptualize the real events in the objective world into linguistic events, they often choose to profile or conceal some elements of linguistic events. Thus, the various types of logical combination of the three elements of linguistic events can be acquired and shown in Table 1 .

Table 1

Combinations of the Three Elements of Linguistic Events

\begin{tabular}{llll}
\hline \multirow{2}{*}{ Types of combinations } & \multicolumn{3}{c}{ Elements of linguistic events } \\
\cline { 2 - 4 } & \multicolumn{1}{c}{ the attribute $(\mathrm{a})$} & the space $(\mathrm{s})$ & the time $(\mathrm{t})$ \\
\hline Combination I & Concealing & Concealing & Concealing \\
Combination II & Profiling & Concealing & Concealing \\
Combination III & Concealing & Profiling & Concealing \\
Combination IV & Concealing & Concealing & Profiling \\
Combination V & Profiling & Profiling & Concealing \\
Combination VI & Profiling & Concealing & Profiling \\
Combination VII & Concealing & Profiling & Profiling \\
Combination VIII & Profiling & Profiling & Profiling \\
\hline
\end{tabular}

According to table 1, combination I conceals all the elements of a linguistic event and can be called the zero combination. Combination II only profiles the attribute of a linguistic event so that it can be named the attributive combination. Accordingly, combination III, IV, V, VI, VII and VIII can be respectively called the spatial combination, the temporal combination, the attributive-spatial combination, the attributive-temporal combination, the spatial-temporal combination and the attributive-spatial-temporal combination.

\section{Types of linguistic events}

According to the combinations described in table 1, linguistic events can be divided into eight types: the zero events, the attributive events, the spatial events, the temporal events, the attributive-spatial events, the attributive-temporal events, the spatial-temporal events and the attributive-spatial-temporal events. Thus, the types of linguistic events can also be expressed as the following set:

$$
\mathrm{E}=\{\mathrm{E} 0, \mathrm{Ea}, \mathrm{Es}, \mathrm{Et}, \mathrm{Ea}-\mathrm{Es}, \mathrm{Ea}-\mathrm{Et}, \mathrm{Es}-\mathrm{Et}, \mathrm{Ea}-\mathrm{Es}-\mathrm{Et}\}
$$


Gan / Sentence Meaning Comprehension Strategies for Foreign Language Learners: Attribute-space-time Based Events...

Where "E" refers to the events, " $E_{0}$ ", " $E_{a}$ ", " $E_{s}$ ", " $E_{t}$ ", " $E_{a}-E_{s}$ ", " $E_{a}-E_{t}$ ", " $E_{s}-E_{t}$ " and " $E_{a}-E_{s}-E_{t}$ " respectively indicates the zero events, the attributive events, the spatial events, the temporal events, the attributive-spatial events, the spatial-temporal events, the spatial-temporal events and the attributive-spatial-temporal events.

Since the zero events are logically impossible to exist in language, the types of linguistic events actually consist of the following seven types, namely:

$$
\mathrm{E}=\{\mathrm{Ea}, \mathrm{Es}, \mathrm{Et}, \mathrm{Ea}-\mathrm{Es}, \mathrm{Ea}-\mathrm{Et}, \mathrm{Es}-\mathrm{Et}, \mathrm{Ea}-\mathrm{Es}-\mathrm{Et}\}
$$

According to Viewpoint 2, the present study further argues that a linguistic event is either the state or change of a single object in the three dimensions embodied in the three elements, or the state or change of the relationship between two objects in the three dimensions embodied in the three elements, or both of them. For example, the linguistic event "the flower is red" describes the state or change (i.e. "red") of a single object (i.e. "the flower"); the Linguistic event "sons assemble fathers" describes the state or change of the relationship (i.e. "assembling") between two objects (i.e. "sons" and "fathers"); and the linguistic event "this flower is red and that one is different from this one" expresses both the state or change (i.e. "red") of a single object (i.e. "this flower") and the state or change of the relationship (i.e. "different") between two objects (i.e. "this one" and "that one"). This study named the first kind of event "Feature (F)", the second kind of event "Relationship (R)" and the third kind of event "Feature-Relationship (F-R)". In this way, linguistic events can also be expressed as a set of features $(\mathrm{F})$, relationships $(\mathrm{R})$, and feature-relationships $(\mathrm{F}-\mathrm{R})$, that is:

$$
\mathrm{E}=\{\mathrm{F}, \mathrm{R}, \mathrm{F}-\mathrm{R}\}
$$

On this basis, linguistic events can further be divided into simple events (SE) and complex events (CE) according to the numbers of features or relationships, or feature-relationships they contain. Simple events refer to events that contain only one feature $(\mathrm{F})$ or one relationship $(\mathrm{R})$ and can be defined as the follows:

$$
\text { SEdef }=\{F 1, F 2, F 3, \ldots, F m\} \wedge\{R 1, R 2, R 3, \ldots, R n\}(m+n=1)
$$

According to formula (5), simple events include simple features (SF) and simple relationships (SR) and can be expressed as the following set:

$$
\mathrm{SE}=\{\mathrm{SF}, \mathrm{SR}\}
$$

Complex events refer to events that contain more than two features $(\mathrm{F})$, two relationships $(\mathrm{R})$ or two featurerelationships (F-R) and can be defined as the follows:

$$
\mathrm{CEdef}=\{\mathrm{F} 1, \mathrm{~F} 2, \mathrm{~F} 3, \ldots, \mathrm{Fm}\} \wedge\{\mathrm{R} 1, \mathrm{R} 2, \mathrm{R} 3, \ldots, \mathrm{Rn}\}(\mathrm{m}+\mathrm{n} \geq 2)
$$

According to formula (7), complex events include complex features (CF), complex relationships (CR) and complex feature-relationships $(\mathrm{C}<\mathrm{F}-\mathrm{R}>)$ and can be expressed as the following set:

$$
\mathrm{CE}=\{\mathrm{CF}, \mathrm{CR}, \mathrm{C}<\mathrm{F}-\mathrm{R}>\}
$$

According to formula (6) and (8), linguistic events can be further expressed as follows:

$$
\mathrm{E}=\{\mathrm{SF}, \mathrm{SR}, \mathrm{CF}, \mathrm{CR}, \mathrm{C}<\mathrm{F}-\mathrm{R}>\}
$$

Finally, permuting formula (9) with formula (3), the present study finds that there are logically 69 basic types of linguistic events, as shown in Table 2. 
Table 2

Basic Types of Linguistic Events

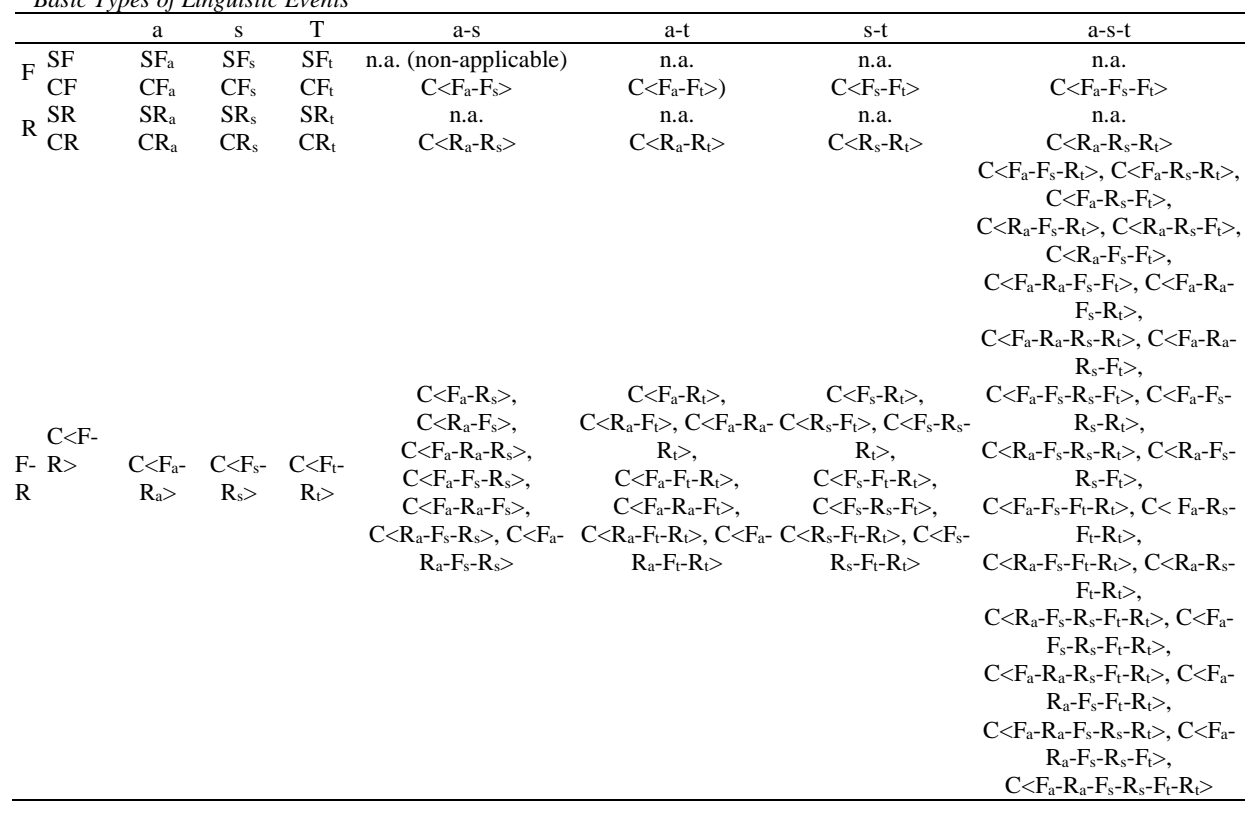

According to table 2, the attributive events $\left(\mathrm{E}_{\mathrm{a}}\right)$ which only profile the attribute of linguistic events can be further divided into five types: simple attributive features $\left(\mathrm{SF}_{\mathrm{a}}\right)$, complex attributive features $\left(\mathrm{CF}_{\mathrm{a}}\right)$, simple attributive relationships $\left(\mathrm{SR}_{\mathrm{a}}\right)$, complex attributive relationships $\left(\mathrm{CR}_{\mathrm{a}}\right)$ and complex attributive featuresattributive relationships $\left(\mathrm{C}<\mathrm{F}_{\mathrm{a}}-\mathrm{R}_{\mathrm{a}}>\right)$.

Similarly, spatial events $\left(\mathrm{E}_{\mathrm{s}}\right)$ which only profile the space can also be further divided into five types: simple spatial features $\left(\mathrm{SF}_{\mathrm{s}}\right)$, complex spatial features $\left(\mathrm{CF}_{\mathrm{s}}\right)$, simple spatial relationships $\left(\mathrm{SR}_{\mathrm{s}}\right)$, complex spatial relationships $\left(\mathrm{CR}_{\mathrm{s}}\right)$ and complex spatial features-spatial relationships $\left(\mathrm{C}<\mathrm{F}_{\mathrm{s}}-\mathrm{R}_{\mathrm{s}}>\right)$.

Temporal events $\left(\mathrm{E}_{\mathrm{t}}\right)$ which only profile the time can be further divided into five types: simple temporal features $\left(\mathrm{SF}_{\mathrm{t}}\right)$, complex temporal features $\left(\mathrm{CF}_{\mathrm{t}}\right)$, simple temporal relationships $\left(\mathrm{SR}_{\mathrm{t}}\right)$, complex temporal relationships $\left(\mathrm{CR}_{\mathrm{t}}\right)$ and complex temporal features-temporal relationships $\left(\mathrm{C}\left\langle\mathrm{F}_{\mathrm{t}}-\mathrm{R}_{\mathrm{t}}\right\rangle\right)$.

Attributive-spatial events $\left(\mathrm{E}_{\mathrm{a}} \mathrm{E}_{\mathrm{s}}\right)$ which profile both the attribute and the space can be further divided into nine types: complex attributive features-spatial features $\left(\mathrm{C}\left\langle\mathrm{F}_{\mathrm{a}}-\mathrm{F}_{\mathrm{s}}\right\rangle\right)$, complex attributive relationships-spatial relationships $\left(C<R_{a}-R_{s}>\right)$, complex attributive features-spatial relationships $\left(C<F_{a}-R_{s}>\right)$, complex attributive relationships-spatial features $\left(\mathrm{C}<\mathrm{R}_{\mathrm{a}}-\mathrm{F}_{\mathrm{s}}>\right)$, complex attributive features-attributive relationships-spatial relationships $\left(C<\mathrm{F}_{\mathrm{a}}-\mathrm{R}_{\mathrm{a}}-\mathrm{R}_{\mathrm{s}}>\right)$, complex attributive features-spatial features-spatial relationships $\left(C<\mathrm{F}_{\mathrm{a}}-\mathrm{F}_{\mathrm{s}}-\mathrm{R}_{\mathrm{s}}>\right)$, complex attributive features-spatial relationships-spatial features $\left(C<\mathrm{F}_{\mathrm{a}}-\mathrm{R}_{\mathrm{a}}-\mathrm{F}_{\mathrm{s}}>\right)$, complex attributive relationships-spatial features-spatial relationships $\left(C<R_{a}-F_{s}-R_{s}>\right)$ and complex attributive features-attributive relationships-spatial features-spatial relationships $\left(C<\mathrm{F}_{\mathrm{a}}-\mathrm{R}_{\mathrm{a}}-\mathrm{F}_{\mathrm{s}}-\mathrm{R}_{\mathrm{s}}>\right)$. 
Gan / Sentence Meaning Comprehension Strategies for Foreign Language Learners: Attribute-space-time Based Events...

Attributive-temporal events $\left(\mathrm{E}_{\mathrm{a}} \mathrm{E}_{\mathrm{t}}\right)$ which profile both the attribute and the time can also be further divided into nine types: complex attributive features-temporal features $\left(C<\mathrm{F}_{\mathrm{a}}-\mathrm{F}_{\mathrm{t}}>\right)$, complex attributive relationshipstemporal relationships $\left(C<R_{a}-R_{t}>\right)$, complex attributive features-temporal relationships $\left(C<F_{a}-R_{t}>\right)$, complex attributive relationships-temporal features $\left.\left(C<R_{a}-F_{t}\right\rangle\right)$, complex attributive features-attributive relationshipstemporal relationships $\left.\left(C<\mathrm{F}_{\mathrm{a}}-\mathrm{R}_{\mathrm{a}}-\mathrm{R}_{\mathrm{t}}\right\rangle\right)$, complex attributive features-temporal features-temporal relationships $\left(\mathrm{C}\left\langle\mathrm{F}_{\mathrm{a}}-\mathrm{F}_{\mathrm{t}}-\mathrm{R}_{\mathrm{t}}\right\rangle\right)$, complex attributive features-temporal relationships-temporal features $\left(\mathrm{C}\left\langle\mathrm{F}_{\mathrm{a}}-\mathrm{R}_{\mathrm{a}}-\mathrm{F}_{\mathrm{t}}\right\rangle\right)$, complex attributive relationships-temporal features-temporal relationships $\left.\left(C<\mathrm{R}_{\mathrm{a}}-\mathrm{F}_{\mathrm{t}}-\mathrm{R}_{\mathrm{t}}\right\rangle\right)$ and complex attributive features-attributive relationships-temporal features-temporal relationships $\left.\left(C<\mathrm{F}_{\mathrm{a}}-\mathrm{R}_{\mathrm{a}}-\mathrm{F}_{\mathrm{t}}-\mathrm{R}_{\mathrm{t}}\right\rangle\right)$.

Spatial-temporal events $\left(\mathrm{E}_{\mathrm{s}}-\mathrm{E}_{\mathrm{t}}\right)$ which profile both the space and the time can be further divided into nine types: complex spatial features-temporal features $\left(\mathrm{C}\left\langle\mathrm{F}_{\mathrm{s}}-\mathrm{F}_{\mathrm{t}}>\right)\right.$, complex spatial relationships-temporal relationships $\left(C<R_{s}-R_{s}>\right)$, complex spatial features-temporal relationships $\left(C<F_{s}-R_{t}>\right)$, complex spatial relationships-temporal features $\left(\mathrm{C}\left\langle\mathrm{R}_{\mathrm{s}}-\mathrm{F}_{\mathrm{t}}>\right)\right.$, complex spatial features-spatial relationships-temporal relationships $\left.\left(C<\mathrm{F}_{\mathrm{s}}-\mathrm{R}_{\mathrm{s}}-\mathrm{R}_{\mathrm{t}}\right\rangle\right)$, complex spatial features-temporal features-temporal relationships $\left(\mathrm{C}\left\langle\mathrm{F}_{\mathrm{s}}-\mathrm{F}_{\mathrm{t}}-\mathrm{R}_{\mathrm{t}}\right\rangle\right)$, complex spatial features-temporal relationships-temporal features $\left.\left(C<\mathrm{F}_{\mathrm{s}}-\mathrm{R}_{\mathrm{s}}-\mathrm{F}_{\mathrm{t}}\right\rangle\right)$, complex spatial relationshipstemporal features-temporal relationships $\left.\left(C<\mathrm{R}_{s}-\mathrm{F}_{\mathrm{t}}-\mathrm{R}_{\mathrm{t}}\right\rangle\right)$ and complex spatial features-spatial relationshipstemporal features-temporal relationships $\left(C<\mathrm{F}_{\mathrm{s}}-\mathrm{R}_{\mathrm{s}}-\mathrm{F}_{\mathrm{t}}-\mathrm{R}_{\mathrm{t}}>\right)$.

Lastly, attributive-spatial-temporal events $\left(\mathrm{E}_{\mathrm{a}}-\mathrm{E}_{\mathrm{s}}-\mathrm{E}_{\mathrm{t}}\right)$ which profile all the elements of linguistic events can be further divided into twenty-seven types: complex attributive features-spatial features-temporal features $\left(\mathrm{C}\left\langle\mathrm{F}_{\mathrm{a}}-\mathrm{F}_{\mathrm{s}}-\mathrm{F}_{\mathrm{t}}\right\rangle\right)$, complex attributive features-spatial relationships-temporal relationships $\left(\mathrm{C}\left\langle\mathrm{R}_{\mathrm{a}}-\mathrm{R}_{\mathrm{s}}-\mathrm{R}_{\mathrm{t}}\right\rangle\right)$, complex attributive features-spatial features-temporal relationships $\left.\left(C<\mathrm{F}_{\mathrm{a}}-\mathrm{F}_{\mathrm{s}}-\mathrm{R}_{\mathrm{t}}\right\rangle\right)$, complex attributive featuresspatial relationships-temporal relationships $\left.\left(C<\mathrm{F}_{\mathrm{a}}-\mathrm{R}_{\mathrm{s}}-\mathrm{R}_{\mathrm{t}}\right\rangle\right)$, complex attributive features-spatial relationshipstemporal features $\left.\left(\mathrm{C}<\mathrm{F}_{\mathrm{a}}-\mathrm{R}_{\mathrm{s}}-\mathrm{F}_{\mathrm{t}}\right\rangle\right)$, complex attributive relatiobships-spatial features-temporal relationships $\left.\left(C<R_{a}-F_{s}-R_{t}\right\rangle\right)$, complex attributive relationships-spatial relationships-temporal features $\left.\left(C<R_{a}-R_{s}-F_{t}\right\rangle\right)$, complex attributive relationships-spatial features -temporal features $\left(C\left\langle R_{a}-F_{s}-F_{t}\right\rangle\right)$, complex attributive featureattributive relatiobships-spatial features-temporal features $\left.\left(C<\mathrm{F}_{\mathrm{a}}-\mathrm{R}_{\mathrm{a}}-\mathrm{F}_{\mathrm{s}}-\mathrm{F}_{\mathrm{t}}\right\rangle\right)$, complex attributive featuresattributive relationships-spatial features-temporal relationships $\left.\left(C<\mathrm{F}_{\mathrm{a}}-\mathrm{R}_{\mathrm{a}}-\mathrm{F}_{\mathrm{s}}-\mathrm{R}_{\mathrm{t}}\right\rangle\right)$, complex attributive featuresattributive relationships-spatial relationships-temporal relationships $\left.\left(C<\mathrm{F}_{\mathrm{a}}-\mathrm{R}_{\mathrm{a}}-\mathrm{R}_{\mathrm{s}}-\mathrm{R}_{\mathrm{t}}\right\rangle\right)$, complex attributive features-attributive relationships-spatial relationships-temporal features $\left.\left(C<\mathrm{F}_{\mathrm{a}}-\mathrm{R}_{\mathrm{a}}-\mathrm{R}_{\mathrm{s}}-\mathrm{F}_{\mathrm{t}}\right\rangle\right)$, complex attributive features-spatial features- spatial relationships-temporal features $\left(C\left\langle\mathrm{~F}_{\mathrm{a}}-\mathrm{F}_{\mathrm{s}}-\mathrm{R}_{\mathrm{s}}-\mathrm{F}_{\mathrm{t}}\right\rangle\right)$, complex attributive featuresspatial features- spatial relationships-temporal relationships $\left(\mathrm{C}<\mathrm{F}_{\mathrm{a}}-\mathrm{F}_{\mathrm{s}}-\mathrm{R}_{\mathrm{s}}-\mathrm{R}_{\mathrm{t}}>\right)$, complex attributive relationships-spatial features- spatial relationships-temporal relationships $\left.\left(C<R_{a}-F_{s}-R_{s}-R_{t}\right\rangle\right)$, complex attributive relationships-spatial features- spatial relationships-temporal features $\left(C<R_{a}-F_{s}-R_{s}-F_{t}>\right)$, complex attributive features-spatial features-temporal features - temporal relationships $\left(\mathrm{C}<\mathrm{F}_{\mathrm{a}}-\mathrm{F}_{\mathrm{s}}-\mathrm{F}_{\mathrm{t}}-\mathrm{R}_{\mathrm{t}}>\right)$, complex attributive features-spatial relationships- temporal features-temporal relationships $\left(C<\mathrm{F}_{\mathrm{a}}-\mathrm{R}_{\mathrm{s}}-\mathrm{F}_{\mathrm{t}}-\mathrm{R}_{\mathrm{t}}>\right)$, complex attributive relationships-spatial features -temporal features- temporal relationships $\left.\left(C<\mathrm{R}_{\mathrm{a}}-\mathrm{F}_{\mathrm{s}}-\mathrm{F}_{\mathrm{t}}-\mathrm{R}_{\mathrm{t}}\right\rangle\right)$, complex attributive relationships-spatial relationships- -temporal features- temporal relationships $\left.\left(C<F_{a}-F_{s}-R_{s}-F_{t}\right\rangle\right)$, complex attributive relationships-spatial features- spatial relationships-temporal features -temporal relationships $\left(C<R_{a}-F_{s}-R_{s}-F_{t}-R_{t}>\right)$, complex attributive features-spatial features- spatial relationships-temporal features -temporal relationships $\left(\mathrm{C}<\mathrm{F}_{\mathrm{a}}-\mathrm{F}_{\mathrm{s}}-\mathrm{R}_{\mathrm{s}}-\mathrm{F}_{\mathrm{t}}-\mathrm{R}_{\mathrm{t}}>\right)$, complex attributive features-spatial features- spatial relationships-temporal features -temporal relationships $\left.\left(C<\mathrm{F}_{\mathrm{a}}-\mathrm{R}_{\mathrm{a}}-\mathrm{R}_{\mathrm{s}}-\mathrm{F}_{\mathrm{t}}-\mathrm{R}_{\mathrm{t}}\right\rangle\right)$, complex attributive features- 
Gan / Sentence Meaning Comprehension Strategies for Foreign Language Learners: Attribute-space-time Based Events...

attributive relationships-spatial features- temporal features -temporal relationships $\left(C<F_{a}-R_{a}-F_{s}-F_{t}-R_{t}>\right)$, complex attributive features- attributive relationships-spatial features- spatial relationships -temporal relationships $\left(\mathrm{C}\left\langle\mathrm{F}_{\mathrm{a}}-\mathrm{R}_{\mathrm{a}}-\mathrm{F}_{\mathrm{s}}-\mathrm{R}_{\mathrm{s}}-\mathrm{R}_{\mathrm{t}}\right\rangle\right)$, complex attributive features- attributive relationships-spatial featuresspatial relationships -temporal features $\left.\left(C<F_{a}-R_{a}-F_{s}-R_{s}-F_{t}\right\rangle\right)$ and complex attributive features- attributive relationships-spatial features- spatial relationships -temporal features-temporal relationships $\left(C<\mathrm{F}_{\mathrm{a}}-\mathrm{R}_{\mathrm{a}}-\mathrm{F}_{\mathrm{s}}-\mathrm{R}_{\mathrm{s}}-\right.$ $\left.\mathrm{F}_{\mathrm{t}}-\mathrm{R}_{\mathrm{t}}>\right)$.

\section{Event structures and the representations}

The above 69 types of linguistic events in table 2 should correspond to 69 linguistic event structures. Since all those event types include not only simple events with simple features and simple relationships, but also complex events with complex features, complex relationships and complex features-relationships; this section firstly manages to represent the event structures of the above five kinds of linguistic events by using the correlative representations in argument-function terms of the predicate logic.

At first, we represent the event structure of a simple feature (SF) as follows:

$\mathrm{F}(\mathrm{z})$

Where the argument $z$ indicates the single object of the feature and the function $F$ (i.e. Feature) indicates the predicate describing the feature of $z$.

The event structure of a simple relationship (SR) can be represented as follows:

$$
\mathrm{R}(\mathrm{x}, \mathrm{y})
$$

Where the arguments $x$ and $y$ respectively refer to two relational objects of the relationship; the function $R$ (i.e. Relationship) refers to the relational predicate describing the relationship between $x$ and $y$.

A complex event is the combination of several simple events. Its representation of event structure can be acquired by connecting the representations of several simple event structures through the propositional logical connectives “ $\wedge$ ”. Thus, the event structure of a complex feature $(\mathrm{CF})$ can be represented as follows:

$$
\mathrm{F} 1(\mathrm{z} 1) \wedge \mathrm{F} 2(\mathrm{z} 2)
$$

Where the arguments $z_{1}$ and $z_{2}$ respectively refer to two objects of two simple features, they can be identical or different; the functions $F_{1}$ and $F_{2}$ respectively refer to predicates of two simple features, which describe the features of $z_{1}$ and $z_{2}$.

Similarly, the event structure of a complex relationship (CR) can be tentatively represented as:

$$
\mathrm{R} 1(\mathrm{x} 1, \mathrm{y} 1) \wedge \mathrm{R} 2(\mathrm{x} 2, \mathrm{y} 2)
$$

Where the arguments $x_{1}$ and $y_{1}, x_{2}$ and $y_{2}$ respectively refer to two pairs of relational objects, which can be identical or different; the function terms $R_{1}$ and $R_{2}$ are relational predicates that respectively describe the relationships between $x_{1}$ and $y_{1}, x_{2}$ and $y_{2}$. 
Gan / Sentence Meaning Comprehension Strategies for Foreign Language Learners: Attribute-space-time Based Events...

Finally, the event structure of a complex feature-relationship $(\mathrm{C}<\mathrm{F}-\mathrm{R}>)$ can be represented as:

$$
\mathrm{F}(\mathrm{z}) \wedge \mathrm{R}(\mathrm{x}, \mathrm{y})
$$

Where the argument $z$ indicates the object of a feature, $x$ and $y$ are two relational objects of a relationship; all the arguments can be identical or different. Function $F$ (Feature) is a predicate describing the feature of $z$; function $R$ (Relationship) is a predicate describing the relationship between $x$ and $y$.

In a word, the event structures of a simple feature (SF), a simple relationship (SR), a complex feature (CF), a complex relationship (CR) and a complex feature-relationship $(\mathrm{C}<\mathrm{F}-\mathrm{R}>)$ can be represented in table 3 :

Table 3

Primary Representations for the Five Basic Event Structures

\begin{tabular}{lc}
\hline Types of events & Representations for event structures \\
\hline SF & $F(z)$ \\
SR & $R(x, y)$ \\
CF & $F_{1}\left(z_{1}\right) \wedge F_{2}\left(z_{2}\right)$ \\
CR & $R_{l}\left(x_{1}, y_{1}\right) \wedge R_{2}\left(x_{2}, y_{2}\right)$ \\
C $<$ F-R $>$ & $F(z) \wedge R(x, y)$ \\
\hline
\end{tabular}

However, the above representations in table 3 are not the specific representations of semantics. Whereas this study regards linguistic events as the whole semantic content of real events (see Viewpoint 3 ), the event structure of a linguistic event should be regarded as a "semantic structure". Thus, the above representations should be further semantically represented by using the typed $\lambda$ calculus of the predicate logic.

Now this study take a simple feature (SF: $F(z)$ ) as an example to illustrate how to carry on the specific semantic representation of this kind of event structure. According to the event structure of the simple feature, the feature must contain the concept " $z$ " of a feature object $z$ and the concept " $F$ " for describing the feature of the object. Assuming that the concept " $z$ " is "John", the formula of its semantic content can be expressed as:

$$
\text { Fo (John') }
$$

Assuming that the concept of " $F$ " is "Run", then its semantic content formula can be written as:

$$
\text { Fo }\left(\lambda z . \operatorname{Run}^{\prime}(\mathrm{z})\right)
$$

If formula (15) is brought into formula (16), the propositional semantic formula (i.e. the representation of the related event structure) can be obtained by the functional application, that is:

$$
\text { Fo }\left(\operatorname{Run}^{\prime}\left(\mathrm{John}^{\prime}\right)\right)
$$

Thus, the event structure of a simple feature can be semantically represented as:

$$
\text { Fo }\left(F^{\prime}\left(z^{\prime}\right)\right)
$$

Then we take the simple relationship (SR: $R(x, y)$ ) as an example to explain the semantic representation of the event structure of this kind of event. According to the event structure of a simple relationship, the relationship must contain the concept " $x$ " of one relational object $x$, the concept " $y$ " of the other relational object $y$ and the concept " $R$ " for judging the relationship between two objects $x$ and $y$. 
Gan / Sentence Meaning Comprehension Strategies for Foreign Language Learners: Attribute-space-time Based Events...

Assuming that the concept " $x$ " corresponds to the concept of "John", the semantic formula of the concept can be written down as:

$$
\text { Fo }\left(J_{o h n}^{\prime}\right)
$$

Assuming that the concept " $y$ " corresponds to the concept "wine", its semantic formula can be expressed as:

$$
\text { Fo (wine' }{ }^{\prime} \text { ) }
$$

And assuming that "R" corresponds to the concept of "Drink", its semantic formula can be written down as:

$$
\text { Fo }\left(\lambda y x . \operatorname{Drink}^{\prime}(\mathrm{y})(\mathrm{x})\right)
$$

According to the functional application, formula (20) is firstly brought into formula (21), and then the semantic formula can be obtained:

$$
\text { Fo }\left(\lambda x \text {. Drink' }\left(\text { wine }^{\prime}\right)(\mathrm{x})\right)
$$

Then, Formula (19) is brought into formula (22), and the propositional semantic formula (i.e., the representation of the event structure) can be finally acquired:

$$
\text { Fo (Drink' ( wine ')( John')) }
$$

Thus, the event structure of a simple relationship can be semantically represented as:

$$
\text { Fo }\left(\mathrm{R}^{\prime}\left(\mathrm{y}^{\prime}\right)\left(\mathrm{x}^{\prime}\right)\right)
$$

By analogy, the event structures of a complex feature (CF), a complex relationship (CR) and a complex feature-relationship $(\mathrm{C}<\mathrm{F}-\mathrm{R}>)$ can be further semantically represented as the following semantic content formulas:

$$
\begin{aligned}
& \text { Fo }\left(F 1^{\prime}\left(\mathrm{z} 1^{\prime}\right)\right) \wedge \mathrm{Fo}\left(\mathrm{F} 2^{\prime}\left(\mathrm{z} 2^{\prime}\right)\right) \\
& \text { Fo }\left(\mathrm{R} 1^{\prime}\left(\mathrm{y} 1^{\prime}\right)\left(\mathrm{x} 1^{\prime}\right)\right) \wedge \mathrm{Fo}\left(\mathrm{R} 2^{\prime}\left(\mathrm{y} 2^{\prime}\right)\left(\mathrm{x} 2^{\prime}\right)\right) \\
& \text { Fo }\left(\mathrm{F}^{\prime}\left(\mathrm{z}^{\prime}\right)\right) \wedge \mathrm{Fo}\left(\mathrm{R}^{\prime}\left(\mathrm{y}^{\prime}\right)\left(\mathrm{x}^{\prime}\right)\right)
\end{aligned}
$$

\begin{tabular}{|c|c|c|}
\hline Types of events & Semantic representations for event structures & Examples of event structures \\
\hline SF & $F o\left(F^{\prime}\left(z^{\prime}\right)\right)$ & Fo $\left(\operatorname{Run}^{\prime}\left(J_{o h n^{\prime}}\right)\right)$ \\
\hline SR & $F o\left(R^{\prime}\left(y^{\prime}\right)\left(x^{\prime}\right)\right)$ & Fo $\left(\operatorname{Drink}^{\prime}\left(\right.\right.$ wine $\left.^{\prime}\right)\left(\right.$ John $\left.\left.^{\prime}\right)\right)$ \\
\hline $\mathrm{CF}$ & $F o\left(F_{l}^{\prime}\left(z_{1}\right)\right)$ & Fo $\left(\right.$ Dance $^{\prime}\left(\right.$ Mary $\left.\left.^{\prime}\right)\right)$ \\
\hline $\mathrm{CF}$ & $\wedge F o\left(F_{2}^{\prime}\left(z_{2}^{\prime}\right)\right)$ & $\wedge F o\left(\operatorname{Sing}^{\prime}\left(J_{o h n^{\prime}}\right)\right)$ \\
\hline $\mathrm{CR}$ & $\operatorname{Fo}\left(R_{l}^{\prime}\left(y_{1}^{\prime}\right)\left(x_{1}^{\prime}\right)\right)$ & Fo $\left(\operatorname{Drink}^{\prime}\left(\right.\right.$ wine $\left.^{\prime}\right)\left(\right.$ John $\left.\left.^{\prime}\right)\right)$ \\
\hline & $\wedge F o\left(R_{2}^{\prime}\left(y_{2}^{\prime}\right)\left(x_{2}^{\prime}\right)\right)$ & $\wedge F_{o}\left(\operatorname{Drink}^{\prime}\left(\right.\right.$ water $\left.^{\prime}\right)\left(\right.$ Mary $\left.\left.^{\prime}\right)\right)$ \\
\hline $\mathrm{C}<\mathrm{F}-\mathrm{R}>$ & $\begin{array}{c}F o\left(F^{\prime}\left(z^{\prime}\right)\right) \\
\wedge F o\left(R^{\prime}\left(y^{\prime}\right)\left(x^{\prime}\right)\right)\end{array}$ & $\begin{array}{c}\text { Fo }\left(\text { Dance }^{\prime}\left(\text { Mary }^{\prime}\right)\right) \\
\wedge \text { Fo }\left(\operatorname{Drink}^{\prime}\left(\text { wine }^{\prime}\right)\left(\text { John }^{\prime}\right)\right)\end{array}$ \\
\hline
\end{tabular}

To sum up, the event structures of a simple feature (SF), a simple relationship (SR), a complex feature (CF), a complex relationship (CR) and a complex feature-relationship $(\mathrm{C}<\mathrm{F}-\mathrm{R}>)$ can be semantically represented as Table 4.

Table 4

Semantic Representations for the Five Basic Event Structures 


\section{Conclusion}

This paper first discusses the main contents and limitations of the three-mainstream event-structure theories. These theories study linguistic events from the objective world so that they accord with the basic cognitive knowledge of human beings and are worthy of researchers' attention. However, the current mainstream theories do their researches either from the spatial dimension, or from the time dimension, or from the causal relationship. As a result, all of them face with the dilemma that they are unable to explain some of the linguistic phenomena within their own theoretical frameworks.

To study the event structures from a single dimension will not only lead to one-sidedness of cognition but also run counter to the research trend of the integrated study of event structure. This paper integrates the basic views on "events" in the fields of ontology, philosophy, cognitive science and linguistics, and puts forward a new view of the integrated events which is based on the three viewpoints of the integrated events.

This paper further pointed out that the constituent elements of linguistic events should include three elements of events: the attribute, the space and the time. On this basis, this paper discovers 69 basic types of linguistic events and uses the expression of categorical type logic to represent the event structures of all kinds of linguistic events.

The effects of applying the theories presented in this paper will be discussed in another paper.

\section{References}

Bach, E. (2002). The Algebra of Events. In P. Portner \& B. H. Partee (Eds.), Formal Semantics: The Essential Readings. Oxford: Blackwell Publishers Ltd, 5-16, https://dx.doi.org/10.1002/9780470758335.ch13

Croft, W. (1991). Syntactic Categories and Grammatical Relations: The Cognitive Organization of Information. Chicago, The University of Chicago Press.

Davidson, D. (2001). The Logical Form of Action Sentences. In D. Davidson (Ed.) Essays on Actions \& Events. Oxford University Press, 37-71

Dowty, D. (1979). Word Meaning and Montague Grammar. Reidel Publishing Company.

Grimshaw, J. (1990). Argument structure. Cambridge, The MIT Press.

Gruber, J. S. (1965). Studies in lexical relations. MA: Massachusetts Institute of Technology.

Jackendoff, R. (1990a). Semantic structures. Cambridge, The MIT Press.

Jackendoff, R. (1990b). On Larson's treatment of the double object construction. Linguistic Inquiry, 21(3), 427455.

Jackendoff, R. (2003). Foundation of Language: Brain, Meaning, Grammar, Evolution. Oxford University Press. 
Gan / Sentence Meaning Comprehension Strategies for Foreign Language Learners: Attribute-space-time Based Events...

Maienborn, C. (2008). On Davidsonian and Kimian States. In C. Ileana \& K. Von Heusinger (Eds.), Existence: Semantics and Syntax (pp107-130). Berlin: Springer Science + Business Media B.V. https://dx.doi.org/10.1007/978-1-4020-6197-4_4

Reichenbach, H. (2011). The Tenses of Verbs. In J. C. Meister \& W. Schernus (Eds.), Time: From Concept to Narrative Construct: A Reader, Berlin - Boston: De Gruyter, 1-12. https://dx.doi.org/10.1515/9783110227185.1

Ritter, B., \& Rosen, S. (1998). Delimiting events in syntax. In M. Butt \& W. Geudee, The Projection of Arguments. CSLI, 135-164

Rosen, S. T. (1996). Events and verb classification. Linguistics, 34(2), 191-224. https://dx.doi.org/10.1515/ling.1996.34.2.191

Tenny, C. L. (1994). Aspectual Roles and the Syntax-Semantics Interface. Boston: Kluwer Academic. https://dx.doi.org/10.1007/978-94-011-1150-8

Tenny, C., \& Pustejovsky, J. (2000). A History of Events in Linguistics. In C. Tenny \& J. Pustejovsky, Events as Grammatical Objects: The Converging Perspectives of Lexical Semantics and Syntax. Cambridge University Press, 1-37.

Vendler, Z. (1957). Verbs and Times. The Philosophical Review, 66(2), 143-160. https://doi.org/10.2307/2182371

Verkuyl, H. J. (1972). On the Compositional Nature of the Aspects. Dordrecht: D. Reidel Publishing Company. https://dx.doi.org/10.1007/978-94-017-2478-4 